\title{
Long-Term Results of Hybrid Left Ventricular Reconstruction in the Treatment of Ischemic Cardiomyopathy
}

\author{
Jan Naar $^{1}$ (D) Ivo Skalský $^{2} \cdot$ Andreas Krüger $^{1} \cdot$ Filip Málek $^{1} \cdot$ Kevin Van Bladel $^{3} \cdot$ Lon S. Annest $^{3} \cdot$ Petr Moučka $^{1} \cdot$ \\ Tomáš Mráz ${ }^{1} \cdot$ Vivek Y. Reddy $^{4} \cdot$ Petr Neužil $^{1}$
}

Received: 14 March 2021 / Accepted: 26 April 2021 / Published online: 11 May 2021

(C) The Author(s) 2021

\begin{abstract}
The evidence supporting surgical aneurysmectomy in ischemic heart failure is inconsistent. The aim of the study was to describe long-term effect of minimally invasive hybrid transcatheter and minithoracotomy left ventricular (LV) reconstruction in patients with ischemic cardiomyopathy. Twenty-three subjects with transmural anterior wall scarring, LV ejection fraction 15-45\%, and New York Heart Association class $\geq$ II were intervened using Revivent TC anchoring system. LV end-systolic volume index was reduced from $73.2 \pm 27 \mathrm{ml}$ at baseline to $51.5 \pm 22 \mathrm{ml}$ after 6 months $(p<0.001), 49.9 \pm 20 \mathrm{ml}$ after 2 years $(p<0.001)$, and $56.1 \pm$ $16 \mathrm{ml}$ after 5 years $(p=0.047)$. NYHA class improved significantly at 5 years compared to baseline. Six-min walk test distance increased at 2 years compared to the 6-month visit. Hybrid LV reconstruction using the anchoring system provides significant and durable LV volume reduction during 5-year follow-up in preselected patients with ischemic heart failure.
\end{abstract}

Keywords Hybrid approach · Ischemic cardiomyopathy · Left ventricular aneurysm · Left ventricular reconstruction

$\begin{array}{ll}\text { Abbreviations } \\ \text { CABG } & \text { Coronary artery bypass grafting } \\ \text { EF } & \text { Ejection fraction } \\ \text { HF } & \text { Heart failure } \\ \text { LV } & \text { Left ventricle } \\ \text { LVESVI } & \text { Left ventricular end-systolic volume index } \\ \text { MLHFQ } & \text { Minnesota Living with Heart } \\ & \text { Failure Questionnaire } \\ \text { NT-proBNP } & \text { N-terminal prohormone of brain } \\ & \text { natriuretic peptide } \\ \text { NYHA } & \text { New York Heart Association } \\ \text { 6-MWT } & \text { 6-min walk test }\end{array}$

Associate Editor Marat Fudim oversaw the review of this article

Jan Naar

jan.naar@seznam.cz

1 Department of Cardiology, Na Homolce Hospital, Röentgenova 37/2, 15030 Prague 5, Czech Republic

\section{Introduction}

Heart failure (HF) represents a substantial healthcare issue in developed countries [1, 2], and coronary heart disease is a major cause of $\mathrm{HF}$ with reduced ejection fraction (EF) in the western world [3]. Ischemic HF is associated with shorter survival than non-ischemic HF $[4,5]$, but conventional pharmacological HF therapy is usually not able to be addressed to a specific etiology. Thus, there is a potential for new treatment strategies that could diminish increased mortality and morbidity in patients with ischemic cardiomyopathy.

Exclusion of the scarred, akinetic, or dyskinetic tissue from the left ventricle (LV) might be beneficial in patients that have experienced extensive transmural myocardial infarction in the region of the left anterior descending artery. Remodeling procedure leads to volume reduction

2 Department of Cardiac Surgery, Na Homolce Hospital, Prague, Czech Republic

3 BioVentrix, Inc., San Ramon, CA, USA

4 Cardiac Arrhythmia Service, Mount Sinai Medical Center, New York, USA 
and geometry restoration of the dilated LV that secondarily results in decreased wall tension and lower myocardium energy demand $[6,7]$.

LV reconstruction in ischemic cardiomyopathy has generally been performed in the setting of standard open-heart surgery, where aneurysm resection is usually accompanied by other interventions, mostly coronary artery revascularization [8-12]. Hybrid transcatheter and minithoracotomy LV reconstruction represents a novel treatment option for this cohort of patients with favorable safety and efficacy short-term results [13-15]. It is a remodeling procedure offering minimally invasive access without the need of sternotomy and cardiopulmonary bypass. Higher preoperative LV end-systolic volume index (LVESVI) seems to be an adverse outcome of surgical aneurysmectomy [16, 17] even minimally invasive reconstruction [14].

\section{Methods}

\section{Study Population}

Eligible subjects with ischemic LV dysfunction due to prior myocardial infarction leading to transmural scarring with akinesis or dyskinesis in the anteroseptal, apical, or apicolateral region were enrolled at our center between September 2013 and March 2019. The main inclusion criteria were age 18-80 years, LV EF 15-45\%, New York Heart Association (NYHA) class II-IV, stable HF medication for $>90$ days, and willingness and ability to comply with the study procedures. Localization, size, and transmural extent of the scar were objectified by cardiac magnetic resonance imaging or dynamic computed tomography prior to enrollment. The main exclusion criteria were intracardiac thrombus, myocardial infarction within 90 days before the procedure, systolic pulmonary arterial pressure $>60 \mathrm{mmHg}$ assessed by echocardiography, previous left-sided thoracotomy, and contraindication to open-heart surgery (in case of a complication).

\section{Study Protocol}

The study was designed as prospective and single arm, evaluating 5-year follow-up data. The primary efficacy endpoint was the reduction of LVESVI. Secondary efficacy endpoints were changes in NYHA class, 6-min walk test (6-MWT), Minnesota Living with Heart Failure Questionnaire (MLHFQ), and a level of N-terminal prohormone of brain natriuretic peptide (NT-proBNP). Transthoracic echocardiography, NYHA class, 6-MWT, MLHFQ, and NT-proBNP were obtained at baseline and at 6-month, 2-year, and 5-year follow-up visits. NYHA class and 6-MWT were assessed by different physicians (trained persons), who were blinded to results from preceding follow-up visits. Echo data were evaluated by experienced cardiologist, who was blinded to echo results from other follow-up visits and to timing of echo control. LV volumes and EF were assessed offline on twodimensional echocardiography images with Q-Station software, version 3.8.5 (Philips Healthcare, Andover, USA), using Simpson's biplane method [18]. The study protocol was approved by the institutional ethics committee and complied with the principles outlined in the Declaration of Helsinki. All participants provided written informed consent to participate in the study.

\section{Procedure}

LV reconstruction was performed under general anesthesia as a stand-alone hybrid transcatheter and minimally invasive surgical remodeling procedure on the beating heart utilizing the Revivent TC system (BioVentrix, Inc., San Ramon, USA). As described in detail previously [13, 14], the system consists of delivery equipment and implantable components. The implantable components are created from pairs of titanium anchors covered in polyester cloth, connected by a poly-etherether-ketone tether. A hinged anchor is delivered by internal jugular vein access from the right side of the interventricular septum and the locking anchor by left-sided minithoracotomy. The reconstruction is often completed by exclusively LV-LV placement of the anchor pair on the LV apex. Oral anticoagulation therapy with warfarin was initiated after the procedure and maintained at an international normalized ratio $2.0-2.5$ for the period of at least 3 months.

\section{Statistical Analysis}

To evaluate changes in variables over time, a repeatedmeasures one-way ANOVA using Tukey's multiple comparisons test was used for analysis of complete data and a mixedeffects model using REML (residual maximum likelihood) method with fixed effect type III was applied for the analysis with missing data. An unpaired two-tailed $t$-test or an unpaired two-tailed $t$-test with Welch's correction (where the equal standard deviation was not assumed) were used to evaluate the association between baseline LVESVI and changes in clinical variables. Data are presented as mean \pm standard deviation. Statistical analyses were performed using GraphPad Prism, version 8.2.1 (GraphPad Software, Inc., La Jolla, CA, USA); $p$-values $<0.05$ were considered statistically significant.

\section{Results}

Twenty-three patients ( 15 male, mean age $59 \pm 11$ years) were recruited. Mean LV EF was $32 \pm 7 \%$, mean LVESVI $75 \pm 25$ $\mathrm{ml} / \mathrm{m}^{2}$, and mean NYHA class $2.3 \pm 0.5$. Mean follow-up time 
was 5.1 years (minimum 1.9 years, maximum 7.4 years). Twenty patients completed a 6-month visit, 18 patients a 2year visit, and 11 patients a 5 -year visit. Table 1 details the baseline characteristics of the study participants. Table 2 shows the differences in HF pharmacotherapy at baseline compared to the end of the follow-up.

\section{Procedure and Safety Aspects}

On average, 2.9 anchor pairs were used for reconstruction, of which 1.3 anchor pairs were implanted as LV-LV. The mean total operating time was $204 \pm 50 \mathrm{~min}$, and the mean time for implanting the anchoring system was $77 \pm 34 \mathrm{~min}$.

The anchoring system was successfully implanted in 22 patients $(96 \%)$. In one patient, conversion to sternotomy was indicated due to acute mitral regurgitation caused by chordae impairment. Two patients were subjected to conventional reoperation after 3 days and 6 weeks after LV reconstruction, respectively, due to deteriorating tricuspid valve insufficiency.

Table 1 Preoperative baseline characteristics

\begin{tabular}{|c|c|}
\hline Variable & $n=23$ \\
\hline Age (years) & $59 \pm 11$ \\
\hline Male sex $(n ; \%)$ & $15(65 \%)$ \\
\hline BMI $\left(\mathrm{kg} / \mathrm{m}^{2}\right)$ & $29 \pm 6$ \\
\hline Systolic blood pressure (mmHg) & $137 \pm 19$ \\
\hline Diastolic blood pressure (mmHg) & $79 \pm 11$ \\
\hline NYHA class & $2.3 \pm 0.5$ \\
\hline LVEF (echo, \%) & $32 \pm 7$ \\
\hline 6-MWT (m) & $381 \pm 103$ \\
\hline MLHFQ (points) & 22 \\
\hline LVEDVI (echo; ml/m²) & $107 \pm 27$ \\
\hline LVESVI (echo; ml/ $/ \mathrm{m}^{2}$ ) & $75 \pm 25$ \\
\hline Mitral regurgitation $(0-4)$ & 1.2 \\
\hline Previous CABG/PCI $(n ; \%)$ & $15(65 \%)$ \\
\hline ICD implanted $(n ; \%)$ & $19(83 \%)$ \\
\hline CRT implanted $(n ; \%)$ & $3(13 \%)$ \\
\hline Arterial hypertension $(n ; \%)$ & $14(61 \%)$ \\
\hline Diabetes mellitus $(n ; \%)$ & $5(22 \%)$ \\
\hline Smoker: current/past/never $(n ; \%)$ & $3 / 17 / 3(13 / 74 / 60 \%)$ \\
\hline$\%$ of patients on $\beta$-blocker/ACEI or ARB/MRA & $96 / 91 / 65$ \\
\hline$\%$ of target daily dose of $\beta$-blocker & 37 \\
\hline$\%$ of target daily dose of ACEI/ARB & 50 \\
\hline
\end{tabular}

$A C E I$, angiotensin-converting enzyme inhibitor; $A R B$, angiotensin II receptor blocker; $B M I$, body mass index; $C A B G$, coronary artery bypass grafting; $C R T$, cardiac resynchronization therapy; $I C D$, implantable cardioverter defibrillator; $L V E D V I$, left ventricular end-diastolic volume index; $L V E F$, left ventricular ejection fraction; $L V E S V I$, left ventricular end-systolic volume index; $M L H F Q$, Minnesota Living with Herat Failure Questionnaire; $M R A$, mineralocorticoid receptor antagonist; NYHA, New York Heart Association; PCI, percutaneous coronary intervention; 6-MWT, 6-min walk test
Table 2 Changes in heart failure medical therapy during follow-up

\begin{tabular}{lll}
\hline & $\begin{array}{l}\text { Baseline } \\
(n=19)\end{array}$ & $\begin{array}{l}\text { End of follow-up } \\
(n=19)\end{array}$ \\
\hline \% of target daily dose of ß-blocker & 39 & 27 \\
\% of target daily dose of ACEI/ARB & 51 & 42 \\
\% of patients on MRA & 63 & 74 \\
\% of patients on sacubitril/valsartan & 11 & 26 \\
\hline
\end{tabular}

Differences in background heart failure pharmacotherapy of subjects who finished at least 2-year follow-up comparing the situation at baseline and at the end of the follow-up. ACEI, angiotensin-converting enzyme inhibitor; $A R B$, angiotensin II receptor blocker; $M R A$, mineralocorticoid receptor antagonist

Even at the rest of patients, we observed some tricuspid valve insufficiency progression compared to baseline grade $0.64 \pm$ 0.6 (scale $0-4$ ): $1.68 \pm 0.8$ after 6 months $(p<0.001), 1.18 \pm$ 0.8 after 2 years $(p=0.08)$, and $1.65 \pm 1.0$ after 5 years $(p=$ 0.003 ). Four patients died before their 5 -year follow-up visit: the first patient died 2 weeks after the procedure due to combined shock with multiple organ failure and acute abdomen, the second 4 months after intervention as a consequence of periprocedural ischemic stroke, the third 8 months after the procedure due to lung carcinoma, and the fourth 4 years after the procedure as a result of alcohol abuse. This resulted in allcause mortality rates $4 \%$ at 30 days, $13 \%$ at 2 years, and $24 \%$ at 5 years.

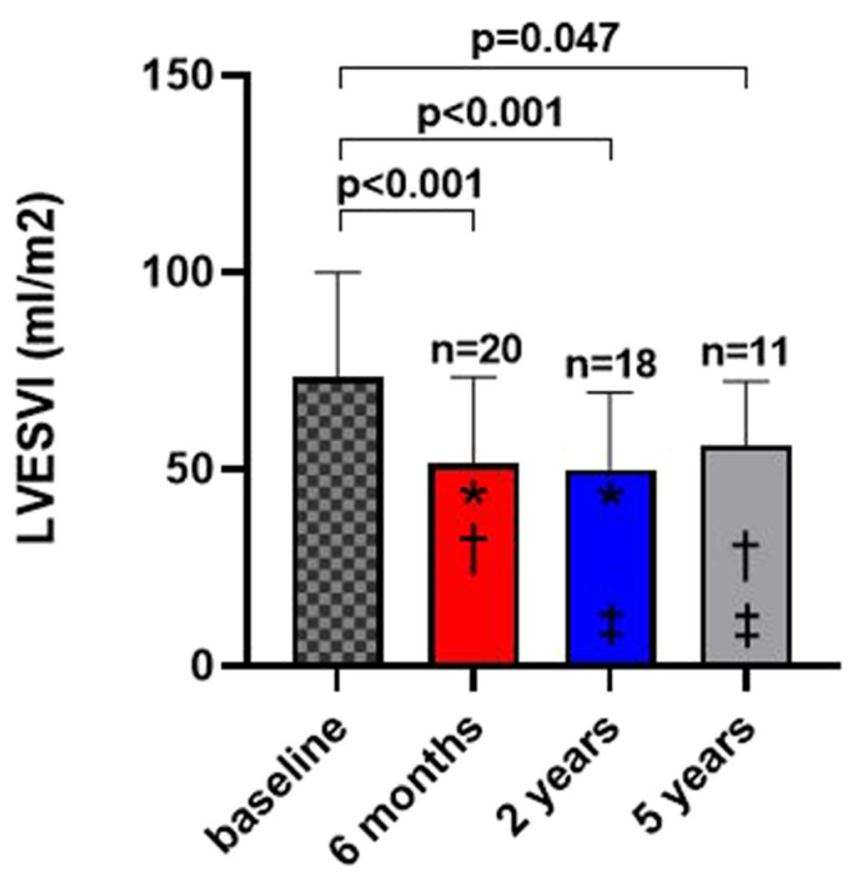

Fig. 1 Change in LVESVI at 6 months, 2 years, and 5 years. Data are

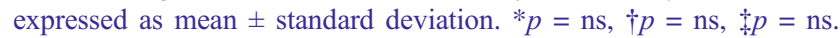
LVESVI, left ventricular end-systolic volume index 


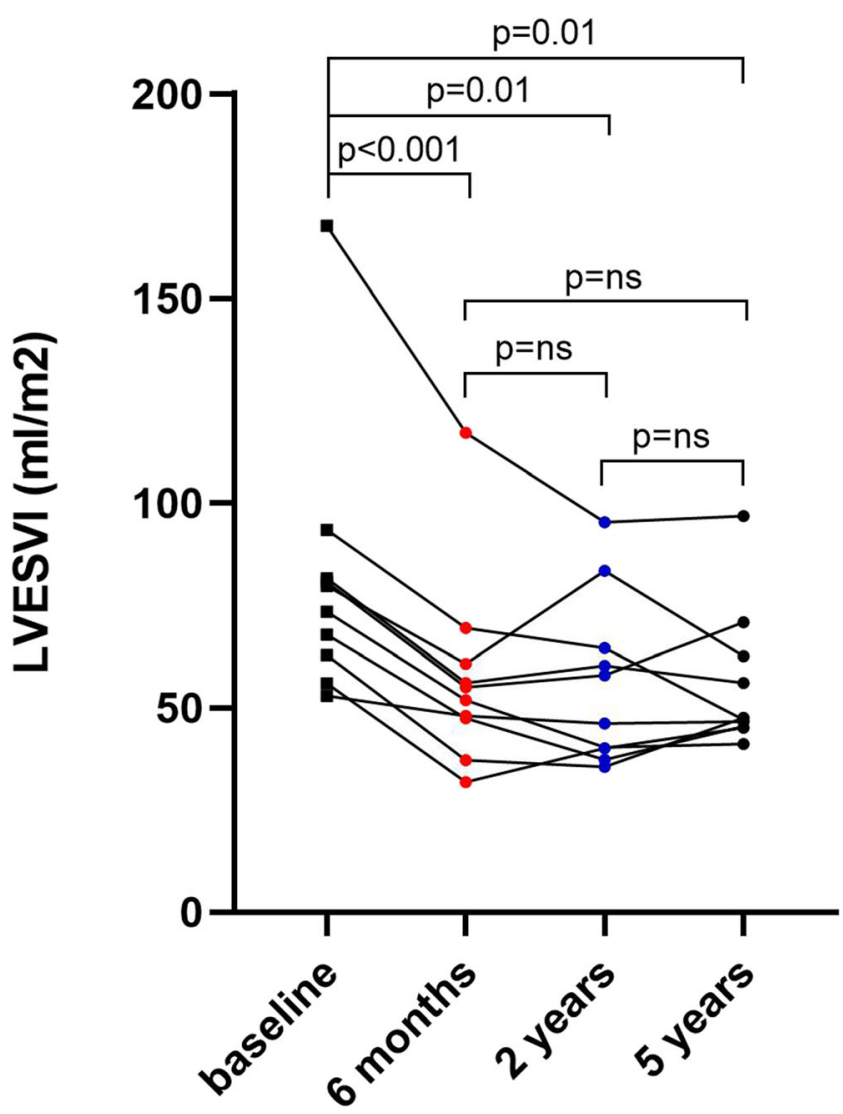

Fig. 2 Individual changes in LVESVI at 6 months, 2 years, and 5 years. LVESVI, left ventricular end-systolic volume index

\section{Effect on Left Ventricular Remodeling}

As shown in Fig. 1, LVESVI was significantly reduced from $73.2 \pm 27 \mathrm{ml}$ at baseline to $51.5 \pm 22 \mathrm{ml}$ after 6 months $(p<0.001), 49.9 \pm 20 \mathrm{ml}$ after 2 years $(p<$ $0.001)$, and $56.1 \pm 16 \mathrm{ml}$ after 5 years $(p=0.047)$.
LVESVI reduction persisted throughout the 5-year follow-up period in individual subjects (Fig. 2). The relative LVESVI reduction after 6 months, 2 years, and 5 years was $30 \%, 33 \%$, and $31 \%$, respectively. LV end-diastolic volume index significantly decreased (Supplemental Figure 1) and the LV EF increased, though significantly only at 2 years (Fig. 3a). Mitral regurgitation was not affected by the procedure (Fig. 3b).

\section{Effect on Symptoms, Functional Capacity, and NT- proBNP Level}

NYHA class decreased significantly after 5 years compared to baseline $(2.3 \pm 0.5$ versus $1.6 \pm 0.7, p=0.01)-$ Fig. $4 \mathrm{a}$. There was a significant improvement in 6-MWT at 2 years compared to the 6-month visit ( $392 \pm 97$ versus $432 \pm 77 \mathrm{~m}, p=$ 0.02 ) and trend to the improvement at 2 years compared to baseline - Fig. 4b. Changes in MLHFQ and NT-proBNP levels were not significant (Fig. 4c-d).

\section{Effect of Baseline LVESVI on Clinical Parameters Relevant to Heart Failure}

Figure 5 suggests that patients with smaller baseline LVESVI may benefit more from the procedure, but the differences did not reach statistical significance.

\section{Effect on Hospitalization Rate}

Supplemental Table 1 shows number of unscheduled allcause and HF hospitalizations comparing 2- or 5-year follow-up period with equivalent 2- or 5-year period prior index procedure.
Fig. 3 Change in left ventricular ejection fraction (a) and mitral regurgitation (b) at 6 months, 2 years, and 5 years. Data are expressed as mean \pm standard deviation. $* p=\mathrm{ns}, \uparrow p=\mathrm{ns}, \ddagger p=$ ns. LV, left ventricle; EF, ejection fraction
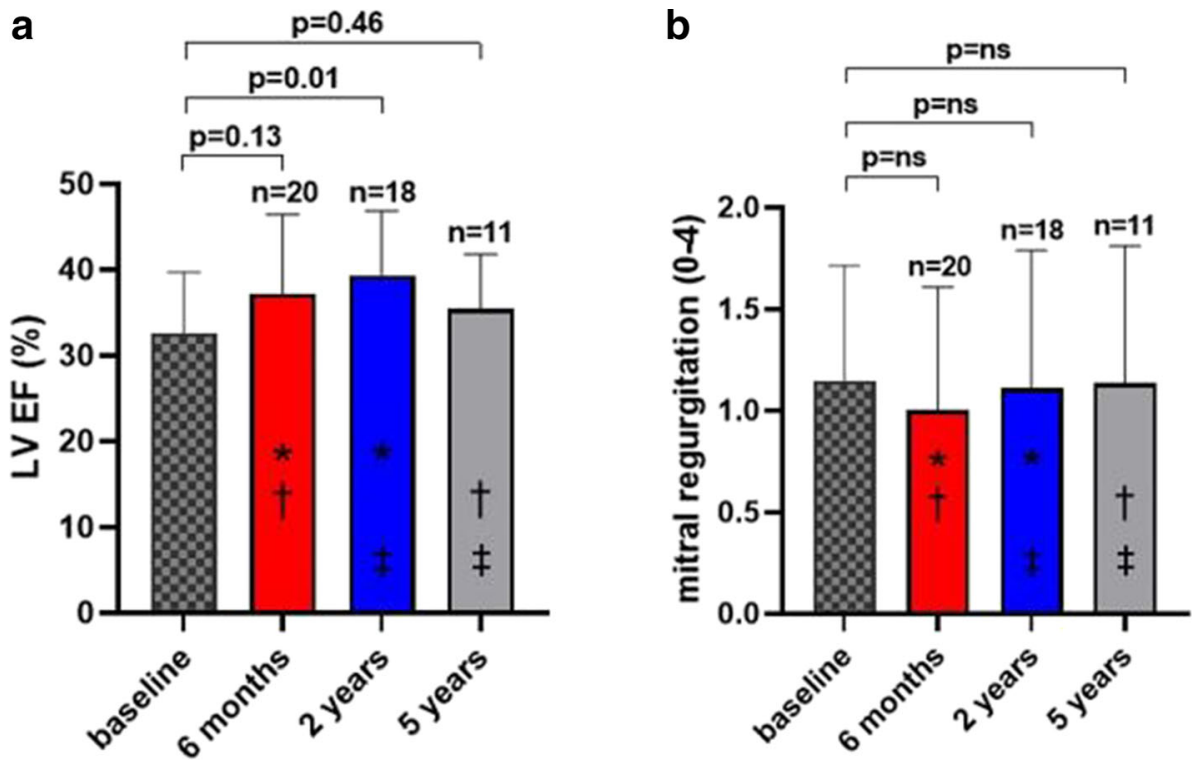
Fig. 4 Effect on clinical parameters relevant to $\mathrm{HF}$ and NT-proBNP at 6 months, 2 years, and 5 years. Data are expressed as mean \pm standard deviation. $* p=$ $\mathrm{ns}, \dagger p=\mathrm{ns}, \ddagger p=\mathrm{ns}$. MLHFQ, Minnesota Living with Heart Failure Questionnaire; NTproBNP, N-terminal prohormone of brain natriuretic peptide; NYHA, New York Heart Association; 6-MWT, 6-min walk test
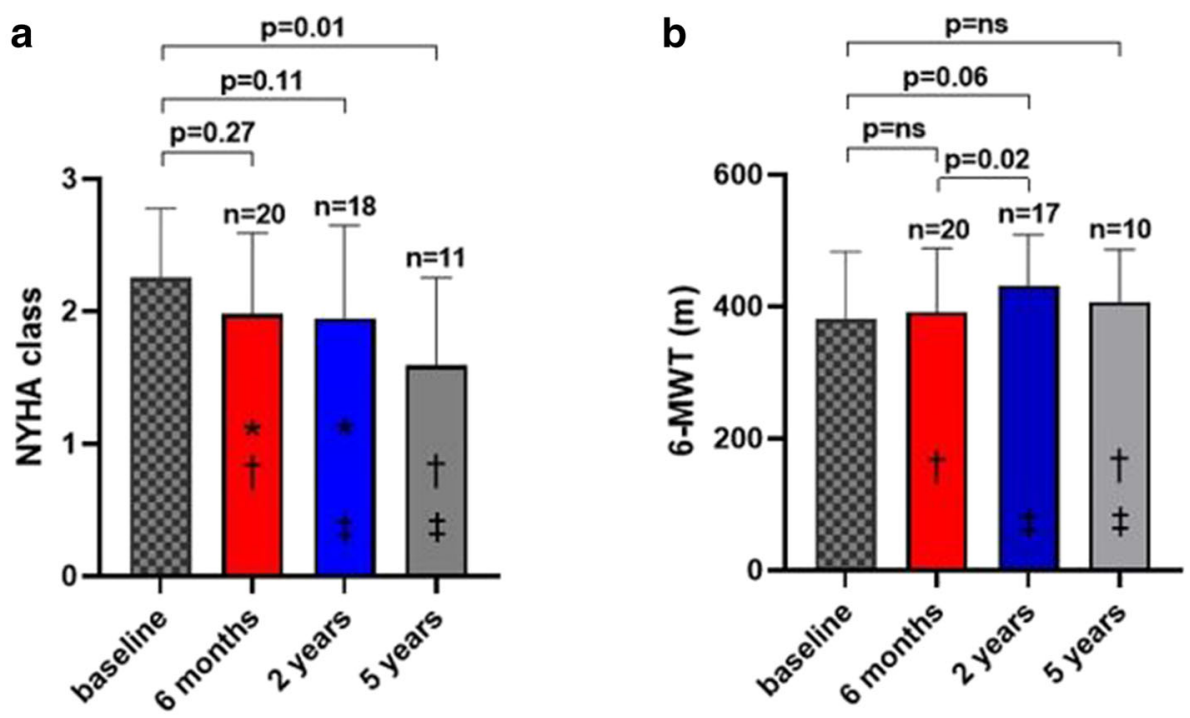

C

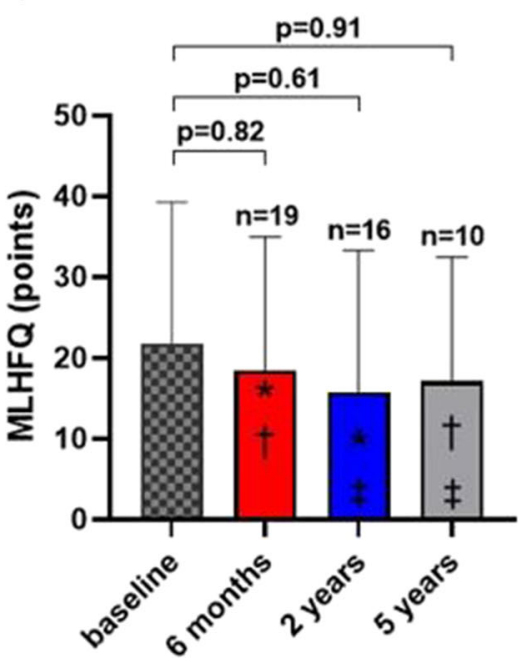

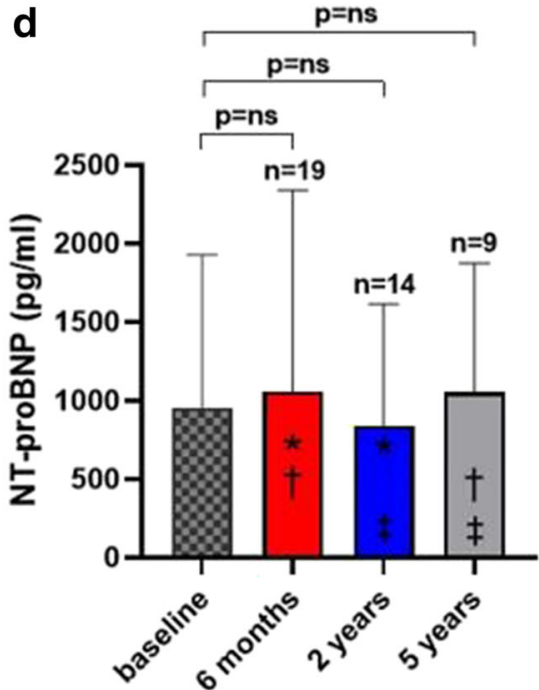

\section{Discussion}

In present study, we have shown that hybrid transcatheter and minithoracotomy LV reconstruction with the Revivent TC anchoring system is a feasible method enabling significant and durable $\mathrm{LV}$ volume reduction (relative LVESVI reduction 30-33\%). LV reverse remodeling effect was accompanied by improvement in NYHA class and 6-MWT in certain parts of the follow-up; however, significant changes in MLHFQ or NT-proBNP were not detected. An additional sub-analysis testing the role of baseline LVESVI on clinical outcome showed a trend towards improvement in all variables, but it did not reach statistical significance.

Regarding surgical LV reconstruction, preliminary data from registries and one small prospective randomized study demonstrated favorable outcomes in surgical LV aneurysmectomy, generally with concomitant coronary artery bypass grafting $(\mathrm{CABG})$, on ventricular volume reduction, functional status, ischemic mitral regurgitation, and HF hospitalization burden [8-11]. Aguiar Ribeiro et al. demonstrated the benefit of LV reconstruction in addition to CABG in patients with ischemic cardiomyopathy in a small prospective randomized controlled singlecenter trial $(n=74)$ [11]. NYHA class significantly improved and the incidence of HF recurrences and rehospitalizations was lower in the LV reconstruction arm. Relative LVESVI reduction in the interventional group was $32 \%$. The largest randomized clinical trial (STICH), which compared CABG versus CABG plus surgical LV aneurysmectomy, failed to prove any benefit of LV reconstruction [12]. However, significant volume reduction was not achieved in the interventional group (relative LVESVI reduction was only 13\%). Post hoc subgroup analyses implied that patients with smaller baseline LV (LVESVI $<60 \mathrm{ml} / \mathrm{m}^{2}$ ) and better LV EF $(\geq 33 \%)$ or patients that achieved postoperative LVESVI $\left(<60-70 \mathrm{ml} / \mathrm{m}^{2}\right)$ may 


\section{2 years}
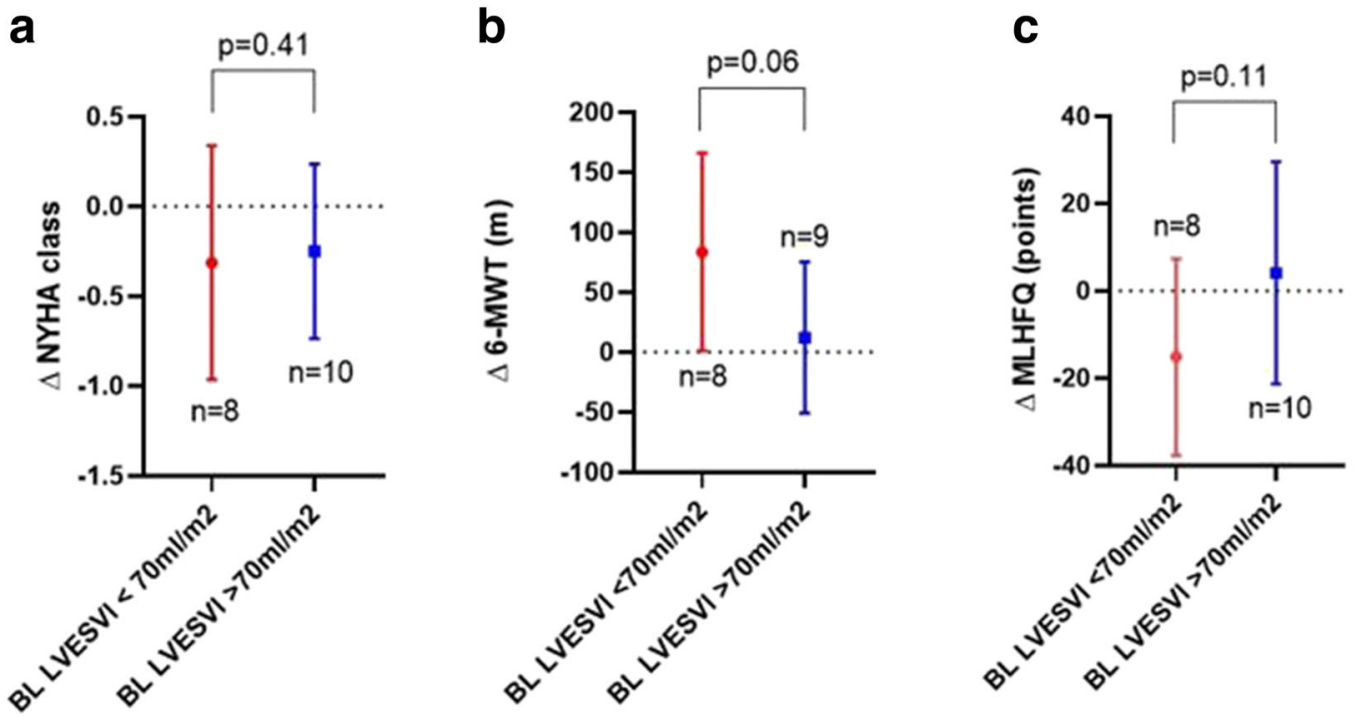

\section{5 years}
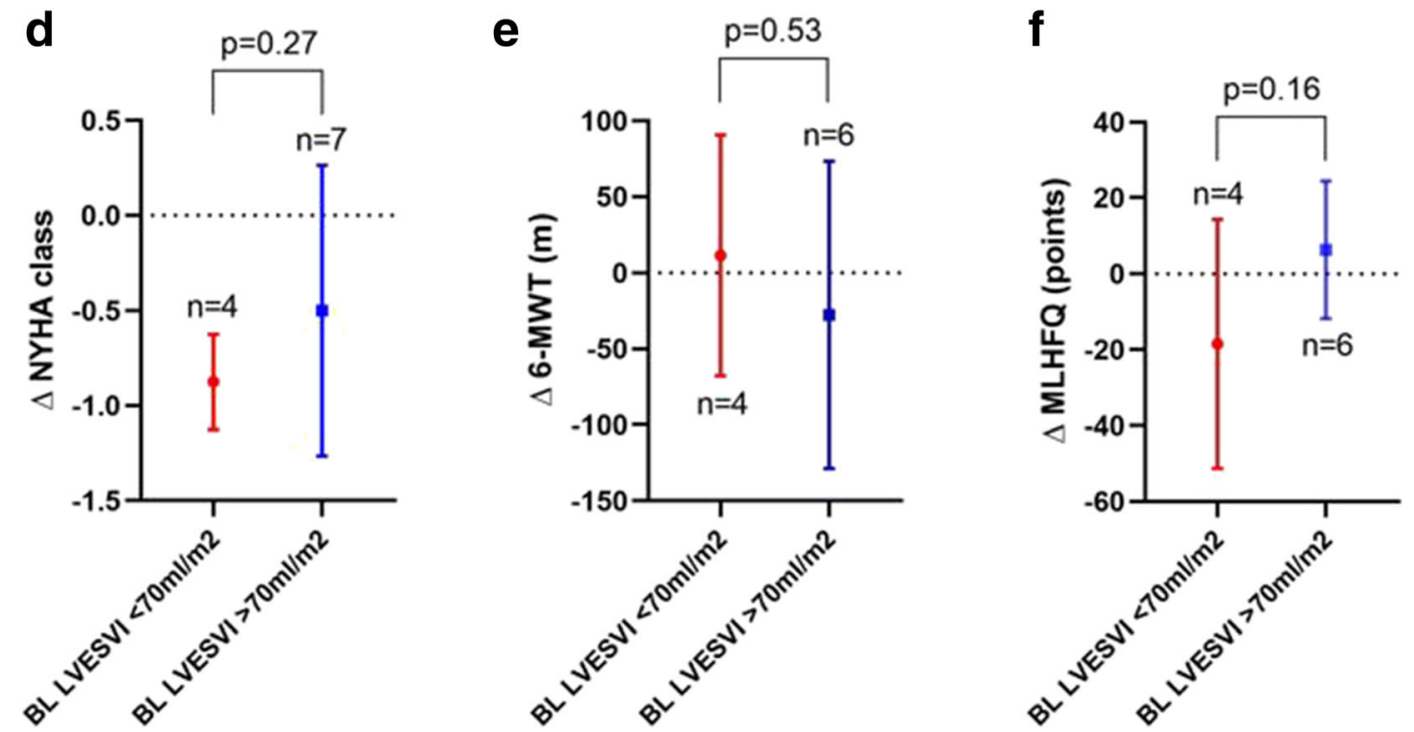

Fig. 5 Effect of baseline LVESVI on clinical parameters at 2 and 5 years. Subgroup analysis based on preoperative LVESVI (cut-off $70 \mathrm{ml} / \mathrm{m}^{2}$ ) showing the effect of index procedure on NYHA $(\mathbf{a}, \mathbf{d}), 6-\mathrm{MWT}(\mathbf{b}, \mathbf{e})$, and MLHFQ (c, f) at 2 and 5 years compared to baseline. Data are

expressed as mean \pm standard deviation of the change. $* p=\mathrm{ns}, \dagger p=\mathrm{ns}$, $\ddagger p=$ ns. BL, baseline; LVESVI, left ventricular end-systolic volume index; MLHFQ, Minnesota Living with Herat Failure Questionnaire; NYHA, New York Heart Association; 6-MWT, 6-min walk test

benefit from aneurysmectomy [16, 17]. Following the publication of neutral STICH trial results, data showing the beneficial effect of surgical aneurysmectomy with adequate $L V$ volume reduction have been reported $[19,20]$. Witowski et al. and Skelley et al. demonstrated, in singlearm studies ( $n=79$ and 87, respectively), significant improvement in symptoms or functional capacity after surgical LV reconstruction performed as a concomitant procedure, combined mostly with CABG. Relative LVESVI reduction was $41 \%$ and $31 \%$, respectively $[21,22]$. Likewise, higher baseline and post-procedure LVESVI signaled adverse outcomes. Recently, Klein et al. presented a multicenter trial with 12-month data after LV reconstruction using the Revivent anchoring system $(n=89)$ [14], of which only $41 \%$ of the patients $(n=35)$ were subjected to a hybrid minimally invasive procedure without sternotomy and concomitant CABG. The study showed statistically significant LV volume reductions, increased EF, and clinical and functional improvement. Low preoperative LVESVI seemed predictive of positive response to remodeling therapy. Adequate volume reduction and early clinical improvement with the Revivent TC 
system was reported also by Wang et al. from a singlecenter series of 26 patients [15].

In the present study, the short-term changes of LVESVI were very similar compared to 1-year data in Klein et al.'s trial. However, the main finding of the present study with potential clinical implication is that the significant volume reduction induced by index procedure persisted throughout the 5-year follow-up. Statistical non-significance of the majority of clinical parameters may be explained partially by the small sample size but may also be due to the less symptomatic cohort enrolled in our study compared to Klein et al. (baseline NYHA $2.3 \pm 0.5$ versus $2.6 \pm 0.5,6$-MWT $381 \pm 103 \mathrm{~m}$ versus $345 \pm 108 \mathrm{~m}$, MLHFQ 22 versus 42 points). Twoand 5-year all-cause mortality of the patients who underwent LV reconstruction in the STICH trial was approximately $50 \%$ higher than in our study. Nevertheless, this comparison is arguable for many reasons - different sample sizes, enrollment period difference more than a decade, or concomitant CABG in STICH trial.

\section{Limitations}

The present study has several limitations. First limitation is a nonrandomized uncontrolled design of the trial. Lack of control group makes the interpretation of changes in NYHA class, MLHFQ, or exercise capacity after 2 or 5 years problematic. It is highly disputable whether the observed improvement in 6MWT at 2 years and NYHA class at 5 years is in relation with the index intervention. Propensity matching with the patients receiving optimal medical therapy could be helpful. There might also be some influence of selection bias on observed variables due to mortality of patients during follow-up, in terms that only patients with more favorable outcome were finally included in the analysis. Similarly, interpretation of pre- and postoperative hospitalization rate is highly disputable in absence of control group, since HF with reduced $\mathrm{EF}$ is characterized by progressive character. Second limitation represents the small sample size that limits especially the statistical analysis of secondary endpoint variables at 5 years and proper subgroup analysis. Nonetheless, despite the fact that the interpretation of secondary endpoints, unscheduled hospitalizations, and subgroup analysis is disputable, to date, this is the largest presented cohort of patients intervened using the Revivent TC system with > 1-year follow-up and the effect on LV remodeling was clearly proven even with this sample size. Third limitation represents the echocardiographic evaluation of LV volumes. Echo data analysis may be impaired by artifacts after anchor implantation. Volume calculation was not done by multiple readers. Fourth limitation is that the background medical therapy of HF did not remain unchanged during the follow-up (dose titration, new initiation of sacubitril/ valsartan in three patients) that may also have an influence on patient outcome.

\section{Conclusion and Prospects}

Hybrid transcatheter and minithoracotomy LV reconstruction using the Revivent TC anchoring system appears to be a feasible treatment method achieving substantial and durable left ventricular volume reduction. It offers the advantage of minimally invasive procedure without need of sternotomy and cardiopulmonary bypass. Long-term effect on clinical parameters and mortality needs to be confirmed in a larger randomized controlled clinical trial.

Supplementary Information The online version contains supplementary material available at https://doi.org/10.1007/s12265-021-10133-9.

Funding This work was supported by the Ministry of Health, Czech Republic, conceptual development of research organization (NHH, 00023884).

\section{Declarations}

Ethical Approval All procedures performed in this study were in accordance with the ethical standards of the institutional research committee and with the Helsinki Declaration of 1975, as revised in 2000.

Informed Consent Informed consent was obtained from all individual participants included in the study.

Conflict of Interest Andreas Krüger and Petr Moučka received scientific grant from BioVentrix, Inc. Kevin Van Bladel and Lon S. Annest have employment relationship with Bioventrix, Inc. Jan Naar, Ivo Skalský, Filip Málek, Tomáš Mráz, Vivek Y. Reddy, and Petr Neužil have no conflict of interest.

Open Access This article is licensed under a Creative Commons Attribution 4.0 International License, which permits use, sharing, adaptation, distribution and reproduction in any medium or format, as long as you give appropriate credit to the original author(s) and the source, provide a link to the Creative Commons licence, and indicate if changes were made. The images or other third party material in this article are included in the article's Creative Commons licence, unless indicated otherwise in a credit line to the material. If material is not included in the article's Creative Commons licence and your intended use is not permitted by statutory regulation or exceeds the permitted use, you will need to obtain permission directly from the copyright holder. To view a copy of this licence, visit http://creativecommons.org/licenses/by/4.0/.

\section{References}

1. Redfield, M. M., Jacobsen, S. J., Burnett, J. C., Mahoney, D. W., Bailey, K. R., \& Rodeheffer, R. J. (2003). Burden of systolic and diastolic ventricular dysfunction in the community: Appreciating the scope of the heart failure epidemic. JAMA, 289, 194-202.

2. Ambrosy, A. P., Fonarow, G. C., Butler, J., Chioncel, O., Greene, S. J., Vaduganathan, M., Nodari, S., Lam, C. S. P., Sato, N., Shah, A. N., \& Gheorghiade, M. (2014). The global health and economic 
burden of hospitalizations for heart failure: Lessons learned from hospitalized heart failure registries. Journal of the American College of Cardiology, 63(12), 1123-1133.

3. Writing Group Members, Mozaffarian, D., Benjamin, E. J., Go, A. S., Arnett, D. K., Blaha, M. J., Cushman, M., Das, S. R., de Ferranti, S., Després, J. P., Fullerton, H. J., Howard, V. J., Huffman, M. D., Isasi, C. R., Jiménez, M. C., Judd, S. E., Kissela, B. M., Lichtman, J. H., Lisabeth, L. D., Liu, S., Mackey, R. H., Magid, D. J., DK, M. G., Mohler 3rd, E. R., Moy, C. S., Muntner, P., Mussolino, M. E., Nasir, K., Neumar, R. W., Nichol, G., Palaniappan, L., Pandey, D. K., Reeves, M. J., Rodriguez, C. J., Rosamond, W., Sorlie, P. D., Stein, J., Towfighi, A., Turan, T. N., Virani, S. S., Woo, D., Yeh, R. W., Turner, M. B., \& American Heart Association Statistics Committee; Stroke Statistics Subcommittee. (2016). Heart disease and stroke statistics-2016 update: A report from the American Heart Association. Circulation, 133(4), e38-e360.

4. Felker, G. M., Shaw, L. K., \& O'Connor, C. M. (2002). A standardized definition of ischemic cardiomyopathy for use in clinical research. Journal of the American College of Cardiology, 39(2), 210-218

5. Gheorghiade, M., \& Bonow, R. O. (1998). Chronic heart failure in the United States: A manifestation of coronary artery disease. Circulation., 97(3), 282-289.

6. Kramer, C. M., Magovern, J. A., Rogers, W. J., Vido, D., \& Savage, E. B. (2002). Reverse remodeling and improved regional function after repair of left ventricular aneurysm. The Journal of Thoracic and Cardiovascular Surgery, 123(4), 700-706.

7. Di Donato, M., Sabatier, M., Toso, A., Barletta, G., Baroni, M., Dor, V., \& Fantini, F. (1995). Regional myocardial performance of non-ischaemic zones remote from anterior wall left ventricular aneurysm. Effects of aneurysmectomy. European Heart Journal, 16(9), 1285-1292.

8. Menicanti, L., Castelvecchio, S., Ranucci, M., Frigiola, A., Santambrogio, C., de Vincentiis, C., Brankovic, J., \& Di Donato, M. (2007). Surgical therapy for ischemic heart failure: Singlecenter experience with surgical anterior ventricular restoration. The Journal of Thoracic and Cardiovascular Surgery, 134(2), 433-441.

9. Cotrufo, M., De Santo, L. S., Della Corte, A., Romano, G., Amarelli, C., De Feo, M., Santarpino, G., Scardone, M., \& Nappi, G. (2008). Acute hemodynamic and functional effects of surgical ventricular restoration and heart transplantation in patients with ischemic dilated cardiomyopathy. The Journal of Thoracic and Cardiovascular Surgery, 135(5), 1054-1060.

10. Athanasuleas, C. L., Buckberg, G. D., Stanley, A. W., Siler, W., Dor, V., Di Donato, M., \& Menicanti, L. (2004). Almeida de Oliveira S, Beyersdorf F, Kron IL, Suma H, Kouchoukos NT, Moore W, McCarthy PM, Oz MC, Fontan F, Scott ML, Accola KA; RESTORE group. Surgical ventricular restoration in the treatment of congestive heart failure due to post-infarction ventricular dilation. Journal of the American College of Cardiology, 44(7), 1439-1445.

11. Aguiar Ribeiro, G. C., Antoniali, F., Lopes, M. M., Costa, C. E., Albuquerque, A. N., \& Franchini, K. G. (2006). Left ventricular reconstruction brings benefit for patients with ischemic cardiomyopathy. Journal of Cardiac Failure, 12(3), 189-194.

12. Jones, R. H., Velazquez, E. J., Michler, R. E., Sopko, G., Oh, J. K., O’Connor, C. M., Hill, J. A., Menicanti, L., Sadowski, Z., Desvigne-Nickens, P., \& Rouleau, J. L. (2009). Lee KL; STICH Hypothesis 2 Investigators. Coronary bypass surgery with or without surgical ventricular reconstruction. The New England Journal of Medicine, 360(17), 1705-1717.

13. Klein, P., Agostoni, P., van Boven, W. J., de Winter, R. J., \& Swaans, M. J. (2019). Transcatheter and minimally invasive surgical left ventricular reconstruction for the treatment of ischaemic cardiomyopathy: Preliminary results. Interactive Cardiovascular and Thoracic Surgery, 28(3), 441-446.

14. Klein, P., Anker, S. D., Wechsler, A., Skalsky, I., Neuzil, P., Annest, L. S., Bifi, M., McDonagh, T., Frerker, C., Schmidt, T., Sievert, H., Demaria, A. N., \& Kelle, S. (2019). Less invasive ventricular reconstruction for ischaemic heart failure. European Journal of Heart Failure, 21(12), 1638-1650.

15. Wang, Y., Xiao, G., Zhang, G., Wang, B., Lin, Z., Saiwha, H. D., You, H., Lai, K., Su, M., Wen, H., Wang, J., Annest, L., \& Tse, G. (2020). Early results of the Revivent TC procedure for treatment of left ventricular aneurysm and heart failure due to ischemic cardiomyopathy. EuroIntervention, 28, EIJ-D-19-00225.

16. Michler, R. E., Rouleau, J. L., Al-Khalidi, H. R., Bonow, R. O., Pellikka, P. A., Pohost, G. M., Holly, T. A., Oh, J. K., Dagenais, F., Milano, C., Wrobel, K., Pirk, J., Ali, I. S., Jones, R. H., Velazquez, E. J., \& Lee, K. L. (2013). Di Donato M; STICH Trial Investigators. Insights from the STICH trial: Change in left ventricular size after coronary artery bypass grafting with and without surgical ventricular reconstruction. The Journal of Thoracic and Cardiovascular Surgery, 146(5), 1139-1145.

17. Oh, J. K., Velazquez, E. J., Menicanti, L., Pohost, G. M., Bonow, R. O., Lin, G., Hellkamp, A. S., Ferrazzi, P., Wos, S., Rao, V., Berman, D., Bochenek, A., Cherniavsky, A., Rogowski, J., \& Rouleau, J. L. (2013). Lee KL; STICH Investigators. Influence of baseline left ventricular function on the clinical outcome of surgical ventricular reconstruction in patients with ischaemic cardiomyopathy. European Heart Journal, 34(1), 39-47.

18. Lang, R. M., Badano, L. P., Mor-Avi, V., Afilalo, J., Armstrong, A., Ernande, L., Flachskampf, F. A., Foster, E., Goldstein, S. A., Kuznetsova, T., Lancellotti, P., Muraru, D., Picard, M. H., Rietzschel, E. R., Rudski, L., Spencer, K. T., Tsang, W., \& Voigt, J. U. (2015). Recommendations for cardiac chamber quantification by echocardiography in adults: An update from the American Society of Echocardiography and the European Association of Cardiovascular Imaging. Journal of the American Society of Echocardiography, 28(1), 1-39.e14.

19. ten Brinke, E. A., Klautz, R. J., Tulner, S. A., Verwey, H. F., Bax, J. J., Schalij, M. J., van der Wall, E. E., Versteegh, M. I., Dion, R. A., \& Steendijk, P. (2010). Long-term effects of surgical ventricular restoration with additional restrictive mitral annuloplasty and/or coronary artery bypass grafting on left ventricular function: Sixmonth follow-up by pressure-volume loops. The Journal of Thoracic and Cardiovascular Surgery, 140(6), 1338-1344.

20. Dor, V., Civaia, F., Alexandrescu, C., Sabatier, M., \& Montiglio, F. (2011). Favorable effects of left ventricular reconstruction in patients excluded from the Surgical Treatments for Ischemic Heart Failure (STICH) trial. The Journal of Thoracic and Cardiovascular Surgery, 141(4), 905-916.e1-4.

21. Witkowski, T. G., ten Brinke, E. A., Delgado, V., Ng, A. C., Bertini, M., Marsan, N. A., Ewe, S. H., Auger, D., Yiu, K. H., Braun, J., Klein, P., Steendijk, P., Versteegh, M. I., Klautz, R. J., \& Bax, J. J. (2011). Surgical ventricular restoration for patients with ischemic heart failure: Determinants of two-year survival. The Annals of Thoracic Surgery, 91(2), 491-498.

22. Skelley, N. W., Allen, J. G., Arnaoutakis, G. J., Weiss, E. S., Patel, N. D., \& Conte, J. V. (2011). The impact of volume reduction on early and long-term outcomes in surgical ventricular restoration for severe heart failure. The Annals of Thoracic Surgery, 91(1), 104111 discussion 111-2.

Publisher's Note Springer Nature remains neutral with regard to jurisdictional claims in published maps and institutional affiliations. 